JARBAS VARGAS NASCIMENTO

MICHELINE MATTEDI TOMAZI

PAULO ROBERTO SODRÉ

\title{
LÍNGUA, LITERATURA E ENSINO
}

SÃO PAULO

2015 


\title{
Língua, Literatura e Ensino
}

\author{
(1) 2015
}

$1^{a}$ edição - 2015

Editora Edgard Blücher Ltda.

ISBN 978-85-8039-119-0 (e-book)

ISBN 978-85-8039-118-3 (impresso)

Nascimento, Jarbas Vargas; Tomazi, Micheline Mattedi; Sodré, Paulo Roberto; "Folha de Rosto, Ficha Catalográfica, Sumário e Apresentação", p. 1-8. In: NASCIMENTO, Jarbas Vargas; TOMAZI, Micheline Mattedi; SODRÉ, Paulo Roberto. Língua, literatura e ensino. São Paulo: Blucher, 2015.

ISBN: 978-85-8039-119-0, DOI 10.5151/9788580391190-0000

\section{Blucher}

Rua Pedroso Alvarenga, $1245,4^{\circ}$ andar

04531-012 - São Paulo - SP - Brazil

Fax 551130792707

Phone 551130785366

editora@blucher.com.br

www.blucher.com.br

Segundo o Novo Acordo Ortográfico, conforme 5a ed. do Vocabulário Ortográfico da Língua Portuguesa, Academia Brasileira de Letras, março de 2009.

É proibida a reprodução total ou parcial por quaisquer meios, sem autorização escrita da Editora.

Todos os direitos reservados pela Editora Edgard Blucher Ltda.

\section{FICHA CATALOGRÁFICA}

Nascimento, Jarbas Vargas

Língua, literatura e ensino [livro eletrônico] /

Jarbas Vargas Nascimento, Micheline Mattedi

Tomazi, Paulo Roberto Sodré. -- São Paulo :

Blucher, 2015.

$3 \mathrm{Mb} ; \mathrm{ePUB}$.

Bibliografia

ISBN 978-85-8039-119-0 (e-book)

ISBN 978-85-8039-118-3 (impresso)

1. Linguística 2. Literatura 3. Língua portuguesa Estudo e ensino I. Título II. Tomazi, Micheline Mattedi III. Sodré, Paulo Roberto

15-0947

CDD 410
Índices para catálogo sistemático:

1. Linguística 


\section{Sumário}

Apresentação

Capítulo 1

DISCURSO, LITERATURA E ENSINO DE LÍNGUA: QUESTÕES PARA O CANCIONEIRO MARIANO DE AFONSO X, O SÁBIO 9

Capítulo 2

IMAGENS DE ATORES SOCIAIS, PAPÉIS E IDENTIDADES NA POESIA DE MARIA ANTONIETA TATAGIBA

Capítulo 3

LEITURA LITERÁRIA E CONHECIMENTO LINGUÍSTICO: CAMINHOS QUE SE ENTRECRUZAM

Capítulo 4

REFLEXÕES ACERCA DO ENSINO DE UMA CULTURA CLÁSSICA

Capítulo 5

ENTRE A LINGUÍSTICA E A LITERATURA: PERCURSOS INTERDISCIPLINARES

Capítulo 6

AS MINHAS MENINAS: CONSTITUIÇÃO E COMPLEXIDADE DISCURSIVAS DAS PERSONAGENS FEMININAS NO CANCIONEIRO DE CHICO BUARQUE

Capítulo 7

O ENSINO DE LITERATURA: EXPERIÊNCIA PARATÓPICA 75 
Capítulo 8

LITERATURA, DESCOBERTA E COGNIÇÃO

85

Capítulo 9

A ESTRUTURA COMPOSICIONAL DO DISCURSO LITERÁRIO 99 


\section{Apresentação}

No exercício profissional escolar, são comuns indagações de professores, geradas por insegurança em trabalhar com metodologias e com estratégias de apoio, que beneficiem seu estudo e de seus alunos sobre discurso literário, cuja materialidade linguística demanda do leitor, concomitantemente, conhecimentos de língua, de literatura e de outras áreas, tais como, a História, a Sociologia, a Filosofia, as Artes, a Psicologia, entre outras. Neste sentido, pesquisadores, professores e mesmo alunos têm levantado dúvidas sobre a maneira mais producente e eficaz de intervenção e organização nas práticas pedagógicas para o ensino de língua e de literatura.

A essa demanda significativa e desafiadora, um número cada vez mais sensível de pesquisadores vem se preocupando e refletindo sobre alternativas, que consigam tornar, paulatinamente, mais preciso o trabalho, que professores e alunos realizam em sala de aula, quando trabalham o discurso literário, espaço complexo dos processos de subjetivação provenientes da instância autoral. Aproximar o ensino das literaturas de língua portuguesa, da língua e da linguística na sala de aula de qualquer nível é um exercício de conexão e de interação, que requer talento pedagógico e formação qualificada, para que os estudantes percebam que o discurso literário agrupa um conjunto de fenômenos socioculturais de diferentes épocas e lugares. Não obstante este esforço, é necessário empreender, igualmente, um constante refletir sobre as práticas pedagógicas, que envolvem o ensino de língua e de literatura, que se apresentam de alta complexidade metodológica.

Como resposta a tais demandas, sempre provisória e, sobretudo, provocativa, os pesquisadores que se dedicam a esse assunto percebem que uma das questões mais relevantes no cenário acadêmico atual de Letras (entenda-se: língua, linguística e literatura) tem sido a da diluição das fronteiras entre essas áreas e a da Educação. Sabe-se que, por muito tempo, os estudos linguísticos, literários e pedagógicos foram observados como áreas estanques destituídas de fluidez e de ramificações que pudessem dar aos alunos do ensino fundamental, médio e superior a noção hoje imprescindível de que esses conhecimentos dialogam, interpenetram-se e complementamse ricamente na formação humana. Tal evidência ganhou mais atenção do fórum público, de modo que as novas diretrizes federais de educação, expressas em Parâmetros curriculares Nacionais e em programas voltados para formação de educadores e de alunos, apontam claramente para as estreitas relações que as áreas de Letras e de Educação exigem. Por este ângulo, não é suficiente refletir e tornar presente, nas salas de aulas, diferentes textos literários, como se estes não mediassem em seu projeto de criação e em sua materialidade linguística, além de intertextos da própria tradição literária, como pensa, por exemplo, Jonathan Culler, contextos, discursos, posicionamentos, como ponderou especialmente Mikhail Bakhtin.

Aderindo a essas diretrizes em que se focaliza, para além da interdisciplinaridade, a interdependência dessas áreas de conhecimento, inequivocamente humanistas, e inspirados por uma pauta de discussão, que considera a importância da fluidez de fronteiras e de valores dos saberes em geral, e dos linguísticos, literários e pedagógicos, em particular, trazemos a público este livro não aleatoriamente intitulado Língua, Literatura e Ensino. Seu norte será o de fomentar reflexões sobre a leitura de discursos literários em estreita consonância com o que se pensa, em termos linguísticos e pedagógicos, nos últimos anos, em variada perspectiva metodológica. 
Nesse viés pontual, os capítulos, que aqui se publicam, procuram, em primeiro lugar, atender àquelas indagações legítimas, e, por conseguinte, buscam promover a diluição das fronteiras entre língua, literatura e ensino, propondo leituras, discussões e análises de poemas das mais diversas realidades históricas, culturais e ideológicas. Passamos, então, a apresentar o teor de cada estudo.

O primeiro capítulo, Discurso, Literatura e ensino de Língua: questões para o cancioneiro mariano de Afonso X, o sábio, assinado por Jarbas Vargas Nascimento e Anderson Ferreira, propõe refletir sobre as particularidades do discurso lítero-religioso medieval de Afonso X, observando sua inscrição na língua portuguesa de então, e na organização formal e estilística de sua enunciação literária, além da tematização do amor, mediado pela figura da mulher. Tais reflexões consideram as relações que a interdisciplinaridade estabelece com outras disciplinas no estudo de diferentes discursos e as possibilidades de intersecções entre língua, literatura e ensino de português, com base na Análise do Discurso, nas abordagens de Maingueneau.

No capítulo seguinte, Imagens de atores sociais, papeis e identidades sociais na poesia de Maria Antonieta Tatagiba, Micheline Mattedi Tomazi e Paulo Roberto Sodré analisam a produção de uma poeta capixaba, Maria Antonieta Tatagiba (1895-1928), numa abordagem interdisciplinar entre língua, literatura e ensino de língua materna e literaturas de língua portuguesa. Os autores procuram promover um diálogo que contribua para a formação do professor em seu trabalho com a poesia, de maneira que o aluno perceba que o texto literário se constitui ideologicamente, ou seja, além de uma construção linguística criativa, ficcional e refinada esteticamente. A bem dizer, para os autores, o texto literário é construído por uma visão de mundo a partir de um fato social marcado por negociações de poder entre gêneros, classes sociais e, particularmente, grupos literários, o que será observado na leitura de poemas da autora, reunidos em Frauta agreste, de 1927.

No terceiro capítulo, de Ernani Terra, intitulado Leitura literária e conhecimento linguístico: caminhos que se entrecruzam, o autor problematiza a fenda existente entre o ensino de língua e de literatura, duas disciplinas de uma mesma área que são tratadas sem que se explorem devidamente suas conexões, contrariando a tendência de que o ensino seja feito a partir de áreas de conhecimento. Com fundamento na Teoria da Enunciação e nos estudos de Maingueneau, o capítulo busca integrar conhecimentos linguísticos e leitura literária, assim como propõe que o ensino da literatura não seja feito numa perspectiva em que se privilegie sua história, mas que tenha o texto como objeto de estudo, do ponto vista linguístico, literário e discursivo.

Carlos Eduardo Mendes de Moraes, no capítulo Reflexões acerca do ensino de uma cultura clássica, apresenta reflexões acerca do ensino de uma Cultura Clássica, que não se opõe aos Estudos Clássicos, como um todo, mas delimita-se a praticá-la em um patamar de atuação possível dentro da complexidade do conceito. As reflexões consistem em estabelecer um objeto e um método, considerando-se o relato (aquele que delineia um percurso de narrações da mais variada gama) como o primeiro que, quando apreciadas segundo uma linha preestabelecida de leitura, oferece consistência ao conceito, enquanto o método diz respeito ao tipo de leitura possível, que se faz na busca da delimitação de um corpus que reúna as vozes para esse relato dos textos literários (ou lidos como literários), que possuem como elemento de ligação sobressaírem-se por permitir a seleção de aspectos fundamentais para o conhecimento de uma Cultura Clássica, através dos tempos, seja para o ensino das línguas românicas, seja para os estudos linguísticos que o fundamentam, ou ainda para as literaturas que o validam e o consolidam.

Em seguida, no quinto capítulo, intitulado Entre a Linguística e a Literatura: percursos interdisciplinares, Maurício Silva trata da interdisciplinaridade entre a Linguística e a Literatura em dois níveis distintos de interação: um nível que parte da Linguística para se chegar à Literatura e que, considerada sua natureza, situa-se num âmbito geral da Educação; e um nível que parte da Literatura para se chegar à Linguística, em que trata de questões relacionadas à pesquisa imanente do texto literário, dentro de uma perspectiva da Análise do Discurso. Desse modo, o trabalho procura contribuir para uma reflexão mais aprofundada e contínua acerca dos possíveis enlaces entre duas formas de abordagem do texto, num sentido lato.

Janaína de Assis Rufino, em As minhas meninas: constituição e complexidade discursivas das personagens femininas no cancioneiro de chico Buarque, título do sexto capítulo, expõe uma reflexão sobre constituição e complexidade discursivas das personagens 
femininas no cancioneiro de chico Buarque de Hollanda. A relação de aproximação entre o romance polifônico conceituado por Bakhtin e as canções buarqueanas é discutida, no intuito de evidenciar que as personagens do cancioneiro desse compositor se constroem da mesma substância das que as do romance polifônico. Neste sentido, o trabalho apresenta um ponto de vista a partir do qual, elas, as personagens, se constituem no e pelo discurso.

Por sua vez, Márcio Rogério de Oliveira Cano e Luciana Soares da Silva, no sétimo capítulo, o ensino de literatura: uma experiência paratópica, ponderam que o ensino de literatura tem sido alvo de críticas nas últimas décadas por não ter conseguido formar o leitor e produtor de práticas literárias e, pelo contrário, criar um distanciamento entre o aluno e o universo literário. Diante dessa constatação, os autores buscam mostrar como a literatura pode ser inserida no universo escolar como uma experiência transdisciplinar e paratópica, que proporciona uma reflexão facilitadora de estudo do objeto literário. Para isso, recorrem às noções trazidas pela Análise do Discurso de linha francesa, em especial, os estudos de Maingueneau acerca da paratopia. Ao fim do capítulo, os autores propõem um encaminhamento didático possível de ser aplicado em sala de aula, utilizando-se poemas de Fernando Pessoa.

o oitavo capítulo, Literatura, descoberta e cognição, é desenvolvido por Vera Bastazin com o objetivo de favorecer o despertar da consciência do educador para a associação entre o poder da língua como objeto de comunicação e o poder da linguagem no âmbito do literário. No enfoque desta dupla perspectiva, a autora pretende destacar a maneira como a desautomatização linguística pode ser um forte aliado no processo de ensino rumo à diversidade do saber pela via do olhar atento para novas formas de ver, entender e interpretar o homem e o mundo. Nesse trabalho, Bastazin apresenta ainda alguns resultados de pesquisa, referentes à leitura e discussão de textos literários e o processo de construção do conhecimento.

Em A estrutura composicional do discurso literário, nono e último capítulo, Gustavo Ximenes Cunha procura compreender a estrutura composicional de produções discursivas do domínio literário. Inicialmente, o autor define as noções de tipo de discurso e de sequência discursiva, a partir das quais ele evidencia que raramente um texto literário será todo narrativo, descritivo ou argumentativo. Em seguida, investiga as relações entre as sequências no nível macrotextual e, depois, a influência dos gêneros do discurso sobre a seleção, a articulação e a marcação linguística das sequências. Por fim, apresenta uma proposta de atividade que indica como o trabalho com a estrutura composicional de discursos literários pode contribuir para a formação do futuro professor de língua portuguesa.

Como se percebe a partir do mapeamento dos capítulos que constam neste livro, nosso objetivo é especialmente o de atender aos professores, que, por um lado, indagam sobre alternativas para o ensino de língua e de literatura, e, por outro, ponderam constantemente suas práticas pedagógicas voltadas, sobretudo, para essas áreas. Procuramos igualmente atraí-los e cativá-los para um trajeto em que o texto literário seja percebido - passe a metáfora conhecida como um caleidoscópio discursivo, em que diversas linguagens e representações se organizam com a finalidade de extrair beleza da língua e argúcia do leitor. Um caleidoscópio, vale repisar, com imenso poder de encantamento e de perturbação, o que fascina os leitores, que se dediquem a mirá-lo em qualquer situação de leitura, e, em particular, numa provocadora, estimulante e renovada sala de aula. 
